\title{
Análise comparativa da densidade de neurônios em áreas corticais de diferentes raças de cães
}

\author{
Alessandra ESTEVES ${ }^{1}$ \\ Irvênia Luiza de Santis \\ PRADA $^{2}$ \\ Ana Flávia de CARVALHO ${ }^{3}$ \\ Celina Furlanetto \\ MANÇANARES ${ }^{3}$ \\ Maria Angélica MIGLINO²
}

Ricardo ROSA ${ }^{3}$

Marco Antônio ROQUETO 3

\section{Correspondência para:}

Alessandra Esteves, Av. Durval Nicolau, 1251 Jardim Recanto do Bosque, 13874-422 - São João da Boa Vista - SP aesteves@usp.broualevet2@yahoo.com.br

Recebido para publicação: 11/12/2006 Aprovado para publicação: 17/08/2008

\author{
1 - Fundação Educacional de Machado, Machado-MG \\ 2 - Faculdade de Medicina Veterinária e Zootecnia da Universidade de São \\ Paulo, São Paulo-SP \\ 3 - Centro Universitário da Fundação de Ensino Octávio Bastos, São João da \\ Boa Vista-SP
}

\section{Resumo}

Foram estudadas e comparadas as densidades neuronais do córtex cerebral de três raças de cães, com tipos constitucionais e aptidões funcionais característicos e distintos entre si. Dos encéfalos foram retirados fragmentos das diferentes áreas do córtex cerebral, correspondentes ao sistema límbico, visual, auditiva, motor, paladar, olfato e à área somestésica. Através de contagem visual-manual, foram buscados dados comparativos, entre áreas cerebrais versus raça associando tipos constitucionais versus aptidão funcional. Os fatores raças, áreas funcionais e hemisférios cerebrais podem ser variáveis dependentes entre si, pois foram encontradas diferenças estatisticamente significativas em valores correspondentes à média de densidade de neurônios das áreas estudadas nas diferentes raças, bem como entre os hemisférios cerebrais. Os resultados permitem concluir que a distribuição quantitativa de neurônios nas diferentes áreas corticais estudadas mostra diferenças significativas que estabelecem correlações com as aptidões funcionais e respectivos tipos constitucionais das raças enfocadas.

\section{Introdução}

Sabe-se que existem diferentes raças de cães com características morfológicas próprias, definindo-se os respectivos tipos morfológicos ou tipos constitucionais. Estes tipos são representados pelo esquema arquitetônico ao qual correspondem indivíduos dotados das mesmas aptidões funcionais. Esta íntima associação entre tipo constitucional morfológico e aptidão funcional constitui assunto de grande relevância em Medicina Veterinária. Assim, por exemplo, o cão da raça Rottweiller que, é do tipo mediolíneo, caracteriza-se por proporções equilibradas entre os diversos diâmetros corporais e apresenta força e resistência médias, tendo como aptidão funcional, originalmente apontar a caça e recolher após o abate. Já no cão da raça Boxer, que é do tipo morfológico brevilíneo, predominam os diâmetros transversais que são mais expressivos que no tipo mediolíneo. Animais dessa raça são possuidores de grande força e foram selecionados com aptidão funcional de guarda e defesa. E, por último, existem os animais longilíneos, como os da raça Dobermann, nos quais a altura e o comprimento predominam sobre os diâmetros transversais. São capazes de desenvolver grande velocidade, sendo usados na perseguição de caça viva ou em corridas. $^{1,2}$

Este estudo propõe quantificar os neurônios de várias áreas corticais em três diferentes raças de cães, ou seja, Boxer, Dobermann e Rottweiller, que apresentam tipos morfológicos e aptidões funcionais diferentes, visando obter informações quantitativas específicas sobre áreas corticais do encéfalo, correspondentes ao sistema límbico, visual, auditiva, locomotor, paladar, 
olfato (Figura 1) e à área da sensibilidade geral (somestésica), que está relacionada a dor, temperatura (frio e calor), tato, pressão e propriocepção (Figura 2), e comparar a quantidade de neurônios de cada uma dessas áreas entre si, entre os hemisférios cerebrais e entre as raças.

\section{Material e Método}

Foram enfocadas neste presente estudo, três raças de cães, ou seja, Boxer, Dobermann e Rottweiler, adquiridos em clínicas veterinárias particulares e Centros de Controle de Zoonoses e de acordo com os princípios éticos de experimentação animal da Comissão de Bioética da FMVZ-USP, protocolo $\mathrm{n}^{\circ} 539 / 2004$, com tipos constitucionais e aptidões funcionais característicos e distintos entre si ${ }^{2}$ então coletados quatro encéfalos de cada raça. Os encéfalos foram fixados em paraformaldeído 4\% de solução tampão fosfato $\mathrm{pH} 7,4$ por três semanas. ${ }^{3} \mathrm{Em}$ cada encéfalo definimos os diferentes sítios do córtex cerebral escolhidos para estudo nos dois hemisférios cerebrais. ${ }^{4}$ Foram retiradas amostras homotípicas destes locais medindo 2 X 0,5 X $1,0 \mathrm{~cm}$. Os fragmentos foram processados seguindo-se a seqüência padronizada nos procedimentos histológicos convencionais: desidratação em álcool, diafanização em xilol e inclusão em histosec ${ }^{\circledR}$ - Merck. ${ }^{5}$ Cada região foi emblocada e cortada com espessura de $5 \mathrm{~mm}$ em micrótomo Leica 2165 e corados com

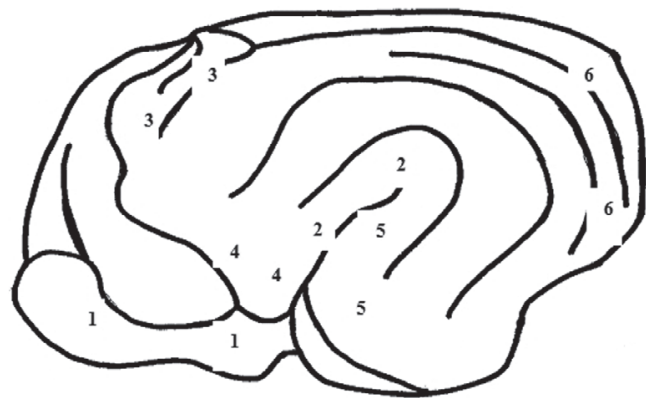

Figura 1 - Esquema da vista lateral esquerda do encéfalo do cão identificando as áreas em que os fragmentos foram retirados conforme os números acima: 1-olfatória; 2- táctil 3-motora; 4-gustativa; 5-auditiva e 6-visual violeta cresil. De cada região foram feitos cinco cortes em série, em cada corte foram contados cinco campos distintos, obtendose deles uma média; das cinco médias obteve-se uma média final para análise estatística. Os cortes foram corados pelo método de coloração de violeta cresil modificado ${ }^{6}$, para facilitar a visualização dos Corpúsculos de Nissl dos corpos de neurônios e assim possibilitar marcar fortemente e individualmente cada célula para posterior contagem. Com base na literatura consultada, optamos pela escolha do método de contagem "visual" por área, como preconizado para sistema nervoso central por Rabinowicz et al. ${ }^{3}$, Avrushchenko ${ }^{7}$ e Michon et al. ${ }^{8}$.

\section{Resultados}

Observa-se, na tabela 1, que a fonte de variação associada à interação tripla foi altamente significativa $(\mathrm{P}<0,01)$, indicando que as variáveis raças, áreas e hemisférios são dependentes entre si. Esta dependência entre os fatores raças, áreas e hemisférios impede a avaliação dos efeitos principais em separado, sendo necessária à realização do(s) desdobramento(s) de dois efeitos, considerando-se o terceiro, fixado.

As estimativas de médias nas áreas e nos hemisférios dentro de cada raça avaliada encontram-se na tabela 2. Para as áreas auditiva e visual do hemisfério cerebral direito, as raças Boxer e Dobermann apresentaram valores médios de neurônios iguais e superiores aos observados para a raça Rottweiller.

Entretanto, para a área olfatória do

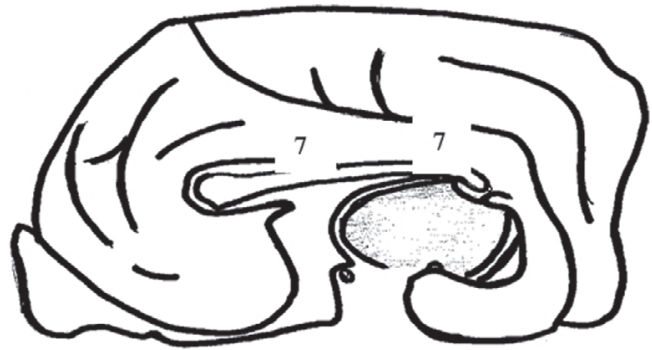

Figura 2 - Esquema da vista sagital medial direita do encéfalo do cão identificando o giro do cíngulo - sistema límbico (7) 
Tabela 1 - Resumo da análise da variância para o número médio dos neurônios avaliados, São Paulo, 2006

\begin{tabular}{lllll}
\hline Fontes de Variação & GL & QM & F & \\
\hline Raça & 2 & 0,270 & 0,060 & ns \\
Área & 6 & 131,043 & 28,520 & $* *$ \\
Hemisfério & 1 & 189,300 & 41,200 & $* *$ \\
Interação Raça x Área & 12 & 30,966 & 6,740 & $* *$ \\
Interação Raça x Hemisfério cerebral & 2 & 64,488 & 14,040 & $* *$ \\
Interação Área x Hemisfério cerebral & 6 & 121,792 & 26,510 & $* *$ \\
Interação Raça x Área x Hemisfério cerebral & 12 & 20,103 & 4,380 & $*$ \\
Resíduo & 294 & 4,594 & &
\end{tabular}

ns $=$ P > 0,05(não-significativo); ** = P<0,01(significativo a $1 \%$ de probabilidade); $\mathrm{GL}=$ grau de liberdade; $\mathrm{QM}=$ quadrado médic $\mathrm{F}=$ fator de variância

Tabela 2 - Estimativas de médias das densidades de neurônios nas áreas e nos hemisférios dentro de cada raça avaliada, São Paulo, 2006

\begin{tabular}{|c|c|c|c|c|c|c|}
\hline \multirow{2}{*}{$\begin{array}{c}\text { Área - Hemisfério cerebral } \\
\text { Auditiva -HC direito }\end{array}$} & \multicolumn{2}{|l|}{ Boxer } & \multicolumn{2}{|c|}{ Dobermann } & \multicolumn{2}{|c|}{ Rottweiller } \\
\hline & 18,138 & $\mathbf{A}$ & 18,683 & A & 11,413 & B \\
\hline Auditiva - HC esquerdo & 9,350 & $\mathbf{A}$ & 7,868 & A & 8,313 & $\mathbf{A}$ \\
\hline Limbica - HC direito & 9,525 & $A$ & 9,245 & $A$ & 10,238 & $A$ \\
\hline Límbica - HC esquerdo & 9,263 & $\mathbf{A}$ & 10,540 & A & 11,625 & $\mathbf{A}$ \\
\hline Gustativa - HC direito & 8,763 & A & 8,100 & $A$ & 8,463 & $A$ \\
\hline Gustativa - HC esquerdo & 7,600 & $\mathbf{A}$ & 7,915 & $\mathbf{A}$ & 8,425 & A \\
\hline Motora - HC direito & 8,600 & $A$ & 8,570 & $A$ & 10,338 & $A$ \\
\hline Motora - HC esquerdo & 7,800 & $\mathbf{A}$ & 8,445 & A & 9,500 & A \\
\hline Olfatória - HC direito & 7,900 & $\mathbf{A}$ & 8,315 & $A$ & 7,713 & $\mathbf{A}$ \\
\hline Olfatória - HC esquerdo & 8,575 & B & 7,003 & B & 13,013 & $\mathbf{A}$ \\
\hline Somestésica - HC direito & 8,300 & $A$ & 8,208 & $A$ & 10,300 & $A$ \\
\hline Somestésica - HC esquerdo & 9,788 & $\mathbf{A}$ & 7,423 & $A$ & 8,725 & A \\
\hline Visual - HC direito & 15,438 & $\mathbf{A}$ & 16,495 & $\mathbf{A}$ & 9,850 & $\mathbf{B}$ \\
\hline Visual - HC esquerdo & 9,275 & $\mathbf{A}$ & 10,285 & $A$ & 10,338 & $A$ \\
\hline
\end{tabular}

Médias em uma mesma linha e seguidas por uma mesma letra, não diferem entre si ao nível de $1 \%$ de probabilidade pelo Teste $t$ de Student

hemisfério cerebral esquerdo, as raças Boxer e Dobermann apresentaram valores médios de neurônios respectivamente iguais e inferiores aos observados para a raça Rottweiller. O desdobramento da interação tripla das raças e das áreas dentro de cada hemisfério avaliado foi expresso na tabela 4. Pela tabela 3, verificou-se que existem diferenças significativas $(\mathrm{P}<0,01)$ observadas nos hemisférios para as seguintes combinações raças e áreas: Boxer - auditiva e visual, Dobermann - auditiva e visual e para Rottweiller - auditiva e olfatória. Para as demais raças e áreas, dentro de cada hemisfério, não existem diferenças significativas $(\mathrm{P}>0,05)$. Para os cães da raça Rottweiller, na área olfatória, o hemisfério cerebral esquerdo apresentou valor médio de neurônios significativamente superior $(\mathrm{P}<0,01)$ ao observado no hemisfério cerebral direito.
As estimativas de médias nas raças e áreas dentro de cada hemisfério, foram expressas na tabela 4. Para as raças e áreas Boxer - auditiva e visual, Dobermann auditiva e visual e Rottweiller - auditiva, valores médios de neurônios significativamente $(\mathrm{P}<0,01)$ superiores foram verificados no hemisfério cerebral direito em relação aos observados no hemisfério cerebral esquerdo.

O desdobramento da interação tripla das raças e dos hemisférios dentro de cada área avaliada foi apresentado na tabela 5 .

$\mathrm{Na}$ tabela 5, diferenças significativas foram observadas para todas as combinações de raças e hemisférios, à exceção da raça Boxer, no hemisfério cerebral esquerdo, para o qual não foram encontradas diferenças significativas $(\mathrm{P}>0,05)$. As estimativas de médias nas raças 
Tabela 3 - Resumo da análise da variância do desdobramento da interação tripla para avaliar as raças e as áreas dentro de cada hemisfério cerebral, São Paulo, 2006

\begin{tabular}{llccc}
\hline \multicolumn{1}{c}{$\begin{array}{c}\text { Fontes de Variação } \\
\text { Raça x Área }\end{array}$} & GL & QM & F & \\
\hline Boxer x Auditiva & 1 & 308,881 & 67,230 & ** \\
Boxer x Límbica & 1 & 0,276 & 0,060 & ns \\
Boxer x Gustativa & 1 & 5,406 & 1,180 & ns \\
Boxer x Motora & 1 & 2,560 & 0,560 & ns \\
Boxer x Olfatória & 1 & 1,823 & 0,400 & ns \\
Boxer x Somestésica & 1 & 8,851 & 1,930 & ns \\
Boxer x Visual & 1 & 151,906 & 33,060 & $* *$ \\
Dobermann x Auditiva & 1 & 467,857 & 101,830 & $* *$ \\
Dobermann x Límbica & 1 & 6,708 & 1,460 & ns \\
Dobermann x Gustativa & 1 & 0,137 & 0,030 & ns \\
Dobermann x Motora & 1 & 0,063 & 0,010 & ns \\
Dobermann x Olfatória & 1 & 6,891 & 1,500 & ns \\
Dobermann x Somestésica & 1 & 2,465 & 0,540 & ns \\
Dobermann x Visual & 1 & 154,256 & 33,580 & $* *$ \\
Rottweiller x Auditiva & 1 & 38,440 & 8,370 & $*$ \\
Rottweiller x Límbica & 1 & 7,701 & 1,680 & ns \\
Rottweiller x Gustativa & 1 & 0,006 & 0,000 & ns \\
Rottweiller x Motora & 1 & 2,806 & 0,610 & ns \\
Rottweiller x Olfatória & 1 & 112,360 & 24,460 & $* *$ \\
Rottweiller x Somestésica & 1 & 9,923 & 2,160 & ns \\
Rottweiller x Visual & 1 & 0,951 & 0,210 & ns \\
\hline
\end{tabular}

ns $=\mathrm{P}>0,05$ (não-significativo); $* *=\mathrm{P}<0,01$ (significativo a $1 \%$ de probabilidade); $\mathrm{GL}=$ grau de liberdade; $\mathrm{QM}=$ quadrado médio; $\mathrm{F}=$ fator de variância

Tabela 4 - Estimativas de médias das densidades neuronais nas raças e áreas dentro de cada hemisfério cerebral avaliado, São Paulo, 2006

\begin{tabular}{|c|c|c|c|c|}
\hline Raças - Áreas & \multicolumn{2}{|c|}{ HC direito } & \multicolumn{2}{|c|}{ HC esquerdo } \\
\hline Boxer - Auditiva & 18,138 & $\mathbf{A}$ & 9,350 & $\mathbf{B}$ \\
\hline Boxer - Límbica & 9,525 & $\mathbf{A}$ & 9,263 & $A$ \\
\hline Boxer - Gustativa & 8,763 & $\mathbf{A}$ & 7,600 & $\mathbf{A}$ \\
\hline Boxer - Motora & 8,600 & $\mathbf{A}$ & 7,800 & A \\
\hline Boxer - Olfatória & 7,900 & $A$ & 8,575 & $A$ \\
\hline Boxer - Somestésica & 8,300 & $\mathbf{A}$ & 9,788 & A \\
\hline Boxer - Visual & 15,438 & $\mathbf{A}$ & 9,275 & $\mathbf{B}$ \\
\hline Dobermann - Auditiva & 18,683 & $\mathbf{A}$ & 7,868 & B \\
\hline Dobermann - Límbica & 9,245 & $\mathbf{A}$ & 10,540 & $\mathbf{A}$ \\
\hline Dobermann - Gustativa & 8,100 & $\mathbf{A}$ & 7,915 & A \\
\hline Dobermann - Motora & 8,570 & $\mathbf{A}$ & 8,445 & A \\
\hline Dobermann - Olfatória & 8,315 & $\mathbf{A}$ & 7,003 & A \\
\hline Dobermann - Somestésica & 8,208 & $\mathbf{A}$ & 7,423 & $A$ \\
\hline Dobermann - Visual & 16,495 & $\mathbf{A}$ & 10,285 & B \\
\hline Rottweiller - Auditiva & 11,413 & $\mathbf{A}$ & 8,313 & $\mathbf{B}$ \\
\hline Rottweiller - Límbica & 10,238 & $\mathbf{A}$ & 11,625 & A \\
\hline Rottweiller - Gustativa & 8,463 & $\mathbf{A}$ & 8,425 & $\mathbf{A}$ \\
\hline Rottweiller - Motora & 10,338 & $\mathbf{A}$ & 9,500 & A \\
\hline Rottweiller - Olfatória & 7,713 & B & 13,013 & A \\
\hline Rottweiller - Somestésica & 10,300 & $\mathbf{A}$ & 8,725 & $A$ \\
\hline Rottweiller - Visual & 9,850 & $\mathbf{A}$ & 10,338 & A \\
\hline
\end{tabular}

Médias em uma mesma linha e seguidas por uma mesma letra, não diferem entre si com $1 \%$ de probabilidade pelo Teste $F$

e hemisférios avaliados dentro de cada área são apresentadas na tabela 6 .

Para as raças Boxer e Dobermann, no hemisfério cerebral direito, foram observados maiores valores médios de neurônios na área auditiva e menores valores médios nas áreas límbica, gustativa, motora, olfatória e somestésica. Contudo, para a raça Rottweiller, no hemisfério cerebral direito, maiores valores médios de neurônios foram verificados nas áreas auditiva, límbica, motora, somestésica e visual. Já para as áreas 
Tabela 5 - Resumo da análise da variância do desdobramento da interação tripla para avaliar as raças e os hemisférios cerebrais dentro de cada área - São Paulo - 2006

\begin{tabular}{lcccc}
\hline Fontes de Variação & GL & QM & F & \\
Raça - Hemisfério cerebral (HC) & & & & \\
\hline Boxer - HC direito & 6 & 133,948 & 29,150 & $* *$ \\
Dobermann - HC direito & 6 & 162,085 & 35,280 & $* *$ \\
Rottweiller - HC direito & 6 & 12,624 & 2,750 & $*$ \\
Boxer - HC esquerdo & 6 & 5,610 & 1,220 & Ns \\
Dobermann - HC esquerdo & 6 & 15,329 & 3,340 & $* *$ \\
Rottweiller - HC esquerdo & 6 & 25,377 & 5,520 & $* *$ \\
\hline
\end{tabular}

ns $=\mathrm{P}>0,05$ (não-significativo); * $=\mathrm{P}<0,05$ (significativo a $5 \%$ de probabilidade); $* *=\mathrm{P}<0,01$ (significativo a $1 \%$ de probabilidade); $\mathrm{GL}=$ grau de liberdade; $\mathrm{QM}=$ quadrado médio; $\mathrm{F}=$ fator de variância

Tabela 6 - Estimativas de médias das densidades de neurônios nas raças e hemisférios cerebrais dentro de cada área avaliada - São Paulo - 2006

\begin{tabular}{|c|c|c|c|c|c|c|c|c|c|c|c|c|c|c|}
\hline \multirow{2}{*}{\begin{tabular}{l|} 
Raças - \\
Hemisférios \\
Boxer-HCD \\
\end{tabular}} & \multicolumn{2}{|c|}{ Auditivo } & \multicolumn{2}{|c|}{ Comportamental } & \multicolumn{2}{|c|}{ Gustativa } & \multicolumn{2}{|c|}{ Motora } & \multicolumn{2}{|c|}{ Olfatória } & \multicolumn{2}{|c|}{ Táctil } & \multicolumn{2}{|c|}{ Visual } \\
\hline & 18,138 & A & 9,525 & $\mathbf{c}$ & 8,763 & $\mathrm{c}$ & 8,600 & $\mathbf{C}$ & 7,900 & $\mathrm{C}$ & 8,300 & $\mathbf{c}$ & 15,438 & B \\
\hline Dobermann-HCD & 18,683 & $A$ & 9,245 & c & 8,100 & c & 8,570 & C & 8,315 & C & 8,208 & c & 16,495 & B \\
\hline Rottweiller-HCD & 11,413 & $A$ & 10,238 & $\mathbf{A}, \mathbf{B}$ & 8,463 & B,C & 10,338 & $A, B$ & 7,713 & c & 10,300 & $\mathbf{A}, \mathbf{B}$ & 9,850 & $\mathbf{A}, \mathbf{B}$ \\
\hline Boxer-HCE & 9,350 & $A$ & 9,263 & $A$ & 7,600 & A & 7,800 & $A$ & 8,575 & A & 9,788 & $A$ & 9,275 & A \\
\hline Dobermann-HCE & 7,868 & B & 10,540 & $A$ & 7,915 & B & 8,445 & $A, B$ & 7,003 & B & 7,423 & B & 10,285 & $A$ \\
\hline Rottweiller-HCE & 8,313 & c & 11,625 & $\mathbf{A}, \mathbf{B}$ & 8,425 & c & 9,500 & c & 13,013 & $A$ & 8,725 & c & 10,338 & B,C \\
\hline
\end{tabular}

Médias em uma mesma linha e seguidas por uma mesma letra, não diferem entre si ao nível de $1 \%$ de probabilidade pelo Teste $t$ de Student

gustativa e olfatória, foram observados os menores valores médios de neurônios no hemisfério cerebral direito, no hemisfério cerebral esquerdo, as áreas límbica e olfatória apresentaram valores médios de neurônios superiores às demais áreas, e menores valores médios de neurônios foram verificados nas áreas auditiva, gustativa, motora, somestésica e visual.

$\mathrm{Na}$ raça Boxer o hemisfério cerebral esquerdo não apresentou diferenças significativas para as várias áreas estudadas. Para a raça Dobermann o hemisfério cerebral esquerdo apresentou valores médios superiores de neurônios para as áreas límbica, motora e visual e valores inferiores nas áreas auditiva, gustativa, olfatória e somestésica.

\section{Discussão}

A classificação das raças de cães proposta por Coren ${ }^{9}$ levou-nos a refletir sobre a possibilidade de existir uma eventual correlação entre os comportamentos diferentes em termos do que este autor chamou de "inteligência de obediência e trabalho", observados nas diversas raças de cães, com características morfológicas de seus correspondentes cérebros. Nesta reflexão, estamos considerando a hipótese de ser o cérebro, o "órgão" de expressão da mente. ${ }^{10}$ Por outro lado, sabe-se que aos diferentes tipos constitucionais apresentados pelas inúmeras raças de cães existentes ${ }^{2}$ estão associadas aptidões funcionais diferenciadas, o que vem ao encontro do mencionado por Coren ${ }^{9}$ em relação aos diversos graus de inteligência de obediência e de trabalho que encontrou ao analisar diferentes grupos raciais desses animais.

Um trabalho importante, que serviu de base para a nossa pesquisa, foi o de Rabinowicz et al. ${ }^{3}$, que focalizou a estrutura do córtex cerebral de homens e mulheres. Em cada encéfalo foram considerados 86 locais escolhidos e em oito campos para cada local, foi avaliada a quantidade de neurônios, astrócitos e neurópilos (contagem estereológica). Além de outros resultados, esse trabalho mostrou que a quantidade de neurônios no hemisfério cerebral esquerdo é maior no grupo das mulheres e no hemisfério cerebral direito é maior no grupo de homens. Portanto, já sabemos que, além de existirem diferenças no córtex cerebral, entre os sexos, o que igualmente pudemos verificar em estudo anterior, em cães ${ }^{6}$, há ainda diferenças entre os hemisférios, o que nos motivou a buscar dados comparativos entre os dois antímeros cerebrais, também. Tsukahara et al. ${ }^{11}$ e Gagliardo et al. ${ }^{12}$ quantificaram respectivamente o número 
total de neurônios no núcleo septal de ratos e no gânglio mesentérico caudal de cães. Utilizaram como método de coloração azul de toluidina e cortes semi finos. Neste presente trabalho utilizamos violeta cresil que é uma técnica descrita para coloração específica de corpos de neurônios, especificamente da substância de Nissl. Entretanto quanto aos cortes, utilizamos cortes em parafina com $5 \mu \mathrm{m}$, o que foi adequado para a contagem destas células, conforme pretendíamos. As pesquisas que mais nos ofereceram embasamento para realizar este trabalho morfométrico de contagem "visual" no sistema nervoso central foram as de Bubenik e Brown ${ }^{13}$, Moryama, Schimada e Goto ${ }^{14}$, Everall et al. ${ }^{15}$, Pakkenberg e Gundersen ${ }^{16}$, Esteves, Prada e Carvalho ${ }^{6}$ e Gittins e Harrison ${ }^{17}$. De fato, estes trabalhos oferecem dados substanciais sobre a amostragem adequada para se inferir a respeito da quantidade total de células na região cortical de interesse. Esteves, Prada e Carvalho ${ }^{6}$ procederam à análise comparativa entre dados pesquisados, principalmente levando-se em conta diferentes áreas cerebrais nos hemisférios cerebrais direito e esquerdo e entre os sexos, para o conhecimento da distribuição e da quantidade de corpos de neurônios nas diferentes áreas corticais do encéfalo. Os cães apresentaram maiores quantidades de corpos de neurônios na área visual $(19,77)$, seguida da comportamental ou límbica $(18,37)$ e não havendo entre as outras áreas cerebrais, diferença significativa. Quanto aos resultados obtidos nesta pesquisa, encontramos diferenças bastante significativas na densidade de neurônios nas diferentes raças estudadas quando comparadas às diversas áreas corticais. Dentre estes resultados as raças Boxer e Dobermann apresentam maior densidade de neurônios na área auditiva no hemisfério cerebral direito em relação às outras áreas corticais desse hemisfério, nos mesmos animais. Por sua vez, a raça Rottweiller apresenta maior quantidade de neurônios nas áreas auditiva, límbica, motora, somestésica e visual do hemisfério cerebral direito em relação ao hemisfério cerebral esquerdo. Neste hemisfério cerebral esquerdo, o Dobermann apresenta maiores quantidades de corpos de neurônios na área visual em relação ao antímero direito e o cão da raça Boxer, na área olfatória. As diferenças encontradas em relação às quantidades de corpos de neurônios das áreas auditiva, límbica, motora, somestésica e visual no hemisfério cerebral esquerdo dos cães da raça Rotweiller em relação ao hemisfério cerebral direito não são significativas e, portanto eventualmente podem ser interpretadas como compatíveis com o modelo de assimetrias anatômicas normais dos organismos.

Admitindo-se a possibilidade das características estruturais das diferentes áreas corticais analisadas estarem intimamente relacionadas com as aptidões funcionais e conseqüentemente com os tipos constitucionais em relação a cada uma das raças estudadas, poder-se-ia inferir que a maior densidade de neurônios da área visual de raça Dobermann e da área olfatória na raça Boxer, no hemisfério cerebral esquerdo em relação ao hemisfério cerebral direito esteja relacionada com as respectivas capacidades de perseguição de caça viva e corrida (Dobermann) e de guarda e defesa (Boxer), conforme as considerações de Prada ${ }^{2}$. De fato, admitindo-se ser o hemisfério esquerdo, como um todo, transdutor do lógico, do racional, é compreensível que durante a perseguição de uma caça viva, o animal esteja utilizando todo o seu aparato sensorial de visão, dentro de um estado de atenção e alerta. Nesse caso, o Dobermann é privilegiado em termos corticais. A mesma consideração pode ser aventada em relação à maior quantidade de neurônios na região olfatória do hemisfério esquerdo do Boxer. Ao desempenhar sua função de guarda e de defesa, essa sua capacidade sensorial tem bases anatômicas para se mostrar exacerbada nos estados de alerta e de atenção. Outras razões devem existir, para explicar os dados obtidos, que fogem totalmente ao alcance desta pesquisa. 


\section{Conclusões}

Os fatores raças, áreas funcionais e hemisférios cerebrais podem ser variáveis dependentes entre si, pois foram encontradas diferenças estatisticamente significativas em valores correspondentes à média de densidade de neurônios das áreas estudadas nas diferentes raças, bem como entre os hemisférios cerebrais. Os resultados permitem concluir que a distribuição quantitativa de neurônios nas diferentes áreas corticais estudadas mostra diferenças significativas que estabelecem correlações com as aptidões funcionais e respectivos tipos constitucionais das raças enfocadas.

\title{
Comparative analisys of neuron densities in cortical areas of different dogs breed
}

\begin{abstract}
s
They were studied and compared the neuronal densities of the cerebral cortex of three dogs races, with constitutional types, characteristic and different functional aptitudes amongst themselves. Of the brain they were solitary fragments of the different areas of the cerebral cortex, corresponding to the system limbic, visual, hearing, motor, palate, sense of smell and to the area somestesic. Through counting appearance-manual, comparative data were looked for, among areas cerebral versus race associating types constitutional versus aptitude. The factors races, functional areas and cerebral hemispheres can be dependent variables amongst themselves, because they were found differences significant estimation in values corresponding to the average of density of neurons of the areas studied in the different races, as well as he/she enters the cerebral hemispheres. The results allow to end that the quantitative distribution of neurons in the different areas studied cortical display significant differences that establish correlations with the aptitudes functional.
\end{abstract}

\section{Referências}

1 PRADA, I. L. S. A alma dos animais. Campos do Jordão: Mantiqueira, 1997. $63 \mathrm{p}$.

2 PRADA, I. L. S. Tipos constitucionais. São Paulo: [s.n.], 1978. [15] f. (Apostila).

3 RABINOWICZ, T.; et al. Courten-Meyrs, G. M. Structure of the cerebral cortex in men and women. Journal of Neuropathology and Experimental Neurology, v. 61, n. 1, p. 46-57, 2002.

4 VON ECONOMO, C.; KOSKINAS, G. N. Die cytoarchitectonik der hirnrinde des erwachsenen menschen. Vienna: Verlag Julius Springer, 1925.

5 TOLOSA, E. M. C. et al. Manual de técnicas para histologia normal e patológica. 2. ed. São Paulo: Manole, 2003. $331 \mathrm{p}$.

6 ESTEVES, A.; PRADA, I. L. S.; CARVALHO, A. F. Comparação do número de corpos neuronais de áreas do córtex cerebral de cães. Brazilian Journal of Veterinary Research and Animal Science, v. 4, n. 5, p. 332-338, 2004.
Key words:

Dogs.

Breeds.

Brain Cortex.

Neurons.

Neuronal density.
7 AVRUSHCHENKO, M. S. Morphometric study of purkinje cells in the dog cerebellar córtex. Byulleten Eksperimental'noi Biologii I Meditsiny, v. 92, n. 9, p. 363-366, 1981.

$8 \mathrm{MICHON}$, J. J. et al. A comparative study of methods of photoreceptor morphometry. Investigative Ophthalmology and Visual Science, v. 32, n. 2, p. 280284, 1991.

9 COREN, S. A inteligência dos cães. Rio de Janeiro: Ediouro, 1996. 248 p.

10 FINGER, S. Minds behind the brain: a history of the pioneers and their discoveries. New York: Oxford University Press, 2000. 347 p.

11 TSUKAHARA, S. et al. Postnatal apoptosis, development, and sex difference in the lateral septum of rats. The Journal of Comparative Neurology. v. 475, p. 177-187, 2004.

12 GAGLIARDO, K. M. et al. Post natal -related changes in the size and total number of neurons in the inferior mesenteric ganglion of dogs. Total number of neurons can be predicted from body weight and ganglion 
volume. Anatomical Record, v. 286A, p. 917-929, 2005.

13 BUBENIK, G. A.; BROWN, G. M. Morphologic sex differences in primate brain areas involved in regulation of reproductive activity. Specialia, v. 29, n. 5, p. 619-621, 1973.

14 MORYAMA, H.; SHIMADA, K.; GOTO, N. Morphometric analysis of neurons in ganglia: geniculate, submandibular, cervical spinal and superior cervical. Okajimas Folia Anatomic Japanese, v. 72, n. 4, p. 185190, 1995.

15 EVERALL, I. P. et al. Comparasion of two methods for the evaluation of neuronal number in the frontal cortex in Alzheimer disease. Journal of Neuropathology and Experimental Neurology, v. 56, n. 11, p. 12021206, 1997.

16 PAKKENBERG, B.; GUNDERSEN, H. J. Neocortical neuron number in humans: effects of sex and age. The Journal of Comparative Neurology, v. 384, n. 2, p. 312-320, 1997.

17 GITTINS, R.; HARRISON, P. J. A quantitative morphometric study of the human anterior cingulate cortex. Brain Research, v. 1013, p. 212-222, 2004.

18 RABINOWICZ, T.; DEAN, D. E.; PETETOT, J. M. C.; CONTEN-MYERS, G. M. Gender differences in the human cerebral cortex: more neurons in males; more processes in female. Journal of Child Neurology, v. 14, n. 2, p. 98-107, 1999. 